NBER WORKING PAPER SERIES

\title{
RULE OF LAW, DEMOCRACY, OPENNESS, AND INCOME: ESTIMATING THE INTERRELATIONSHIPS
}

\author{
Roberto Rigobon \\ Dani Rodrik \\ Working Paper 10750 \\ http://www.nber.org/papers/w10750 \\ NATIONAL BUREAU OF ECONOMIC RESEARCH \\ 1050 Massachusetts Avenue \\ Cambridge, MA 02138 \\ September 2004
}

We thank Vincent Hogan, Aart Kray and Ricardo Hausmann for very useful comments. We also thank the participants at the Macro Seminar at the World Bank for the comments and suggestions. All remaining errors are ours. The views expressed herein are those of the author(s) and not necessarily those of the National Bureau of Economic Research.

C2004 by Roberto Rigobon and Dani Rodrik. All rights reserved. Short sections of text, not to exceed two paragraphs, may be quoted without explicit permission provided that full credit, including $\odot$ notice, is given to the source. 
Rule of Law, Democracy, Openness, and Income: Estimating the Interrelationships Roberto Rigobon and Dani Rodrik

NBER Working Paper No. 10750

September 2004

JEL No. F10, F43, O40, C33

\title{
ABSTRACT
}

We estimate the interrelationships among economic institutions, political institutions, openness, and income levels, using identification through heteroskedasticity (IH). We split our cross-national dataset into two sub-samples: (i) colonies versus non-colonies; and (ii) continents aligned on an EastWest versus those aligned on a North-South axis. We exploit the difference in the structural variances in these two sub-samples to gain identification. We find that democracy and the rule of law are both good for economic performance, but the latter has a much stronger impact on incomes. Openness (trade/GDP) has a negative impact on income levels and democracy, but a positive effect on rule of law. Higher income produces greater openness and better institutions, but these effects are not very strong. Rule of law and democracy tend to be mutually reinforcing.

\author{
Roberto Rigobon \\ Sloan School of Management \\ MIT, Room E52-431 \\ 50 Memorial Drive \\ Cambridge, MA 02142-1347 \\ and NBER \\ rigobon@mit.edu \\ Dani Rodrik \\ John F. Kennedy School of Government \\ Harvard University \\ 79 JFK Street \\ Cambridge, MA 02138 \\ and NBER \\ dani_rodrik@harvard.edu
}




\title{
RULE OF LAW, DEMOCRACY, OPENNESS, AND INCOME:
}

\author{
ESTIMATING THE INTERRELATIONSHIPS
}

Roberto Rigobon and Dani Rodrik

\section{Introduction}

What are the fundamental determinants of the large income gaps that separate different regions of the world? Are high incomes the result of good institutions, or is it economic wealth that enables high-quality institutions? How does democracy affect economic development? Is openness to international trade good for development? For democracy? For the quality of institutions? What role do geographical constraints and advantages play in driving all these? What are the relative contributions to patterns of global inequality of exogenous determinants such as geography versus man-made factors such as institutions?

These are some of the most important questions in the social sciences and among the thorniest to resolve empirically. An immediate difficulty has to do with measurement and quantification. How are concepts such as "institutions" and "geography" to be operationalized? In recent years, economists have developed a number of different proxies for these, which by now are quite common in the cross-country growth literature (even though they often baffle other social scientists). The quality of institutions, for example, is typically measured using survey-based perceptions of expropriation risk or the rule of law. Geography is typically quantified by looking at distance from the equator, an indicator of climate, or some measure of malaria risk.

The far greater difficulty arises with ascertaining causality. Each of the determinants listed above, with the possible exception of purely geographical variables, can be (and probably are) both a cause and an effect. Simple OLS regressions that relate, say, institutional quality and trade to income levels are likely to yield seriously biased results if used to infer the causal impact of right-hand side variables on the left-hand side variable. The standard solution to this conundrum in cross-national work has been to employ an instrumental-variable approach. This entails finding a variable (the instrument) that (a) is exogenous; (b) is correlated with the endogenous variable for which it is instrumenting; and (c) does not influence the dependent variable through any channel other than the relevant endogenous variable. Once such a variable is located, unbiased estimates of the causal effects can be recovered.

This approach has yielded considerable progress in recent years. Several papers in this line of work are particularly noteworthy. Frankel and Romer (FR, 1999) have used a gravity trade equation to derive the geographical component of trade, which they then used as an instrument to estimate the effect of trade on the level of income. Acemoglu, Johnson, and Robinson (AJR, 2001) have used the mortality rate of early European colonists to derive an instrument for institutional quality and to estimate the 
influence of institutions on incomes. Sachs (2003) has used an ecologically-based determinant of malaria incidence to estimate the impact of geography. Rodrik, Subramanian, and Trebbi (RST, 2002) have combined the FR and AJR instruments to run a "horse race" among institutions, trade, and geography and to examine their relative significance in the determination of income.

While the IV approach has paid off, it also has some drawbacks. Most importantly, the requirements for an instrument to be valid (as discussed briefly above) are quite demanding. In particular, it is difficult to come up with truly exogenous variables that also satisfy the exclusion restriction-i.e., indicators that can be argued to influence incomes solely through the determinant for which they are instrumenting. Consequently, the list of plausible instruments that can be used in this line of inquiry is extremely short (and the instruments mentioned in the previous paragraph come close to exhausting it). This results in just-identified specifications, restricts the range of questions that can be posed, and raises interpretational difficulties.

As a result, none of the previously mentioned papers can shed much light on the reverse causality running from income to institutions, trade, or public health. Doing so would require coming up with an instrumental variable for income--a variable that affects income but not any of its determinants. Perhaps for obvious reasons, no-one has yet embarked on such an effort. Also, existing instruments do not allow us to distinguish, say, between economic and political institutions and gauge their respective contributions to economic performance. ${ }^{2}$ There are simply not enough good instruments to answer these important questions. In a similar vein, Dollar and Kraay (2003) have raised questions about the validity of using the AJR and FR instruments simultaneously in order to parse out the separate influences of trade and institutions on incomes, arguing that the predicted values for the endogenous regressors are too collinear and therefore inference is unreliable. $^{3}$

Moreover, existing instruments for institutional quality and trade are correlated strongly with geographical variables and with human capital, raising interpretational questions about what is in fact being identified. For example, Rodriguez and Rodrik (2001) suggest that the FR (1999) findings have more to do with the impact of geography on incomes than with the impact of trade on incomes. Similarly, analysts like Sachs who think geography plays a key role would argue that the AJR (2001) instrument is a standin for the historical impact of geography, and not for the quality of institutions bequeathed by colonial settlers. Glaeser et al. (2004) have argued that settler mortality may simply capture the human capital of the European colonists, rather than early institutional strengths.

\footnotetext{
${ }^{2}$ See however Acemoglu and Johnson (2003) which tries to unbundle two types of economic institutions, which they call property rights institutions and contracting institutions. They use an IV strategy relying on colonial history.

${ }^{3}$ This is essentially the "weak instruments" problem in the context of multiple instruments. RST (2002) argue that this is not a problem when the conventional measure of trade openness is used (as in RST 2000), but becomes one when an alternative measure (due to Alcala and Ciccone 2002) is substituted.
} 
In this paper we pursue an alternative identification strategy which does not have these disadvantages. We rely on a novel approach called Identification through Heteroskedasticity (IH). The IH method does not require an instrumental variable. It achieves identification instead by exploiting plausible differences in the variances of error terms across sub-samples of the data. To see the intuition behind the IH method, consider the pair of equations that describe the relationship between income $(y)$ and institutional quality $(I)$ :

$$
\begin{aligned}
& y=\beta I+\varepsilon \\
& I=\theta y+v
\end{aligned}
$$

where $\varepsilon$ and $v$ are the random shocks to the income and institutions equations respectively. This is an unidentified system. The usual IV trick would be to find a variable that enters the institutions equation (2) but not equation (1). But suppose we can split our data into two sub-samples $A$ and $B$ such that the variance of the shock to the institutions equation $\left(\sigma_{v}^{2}\right)$ is larger in sub-sample $A$ than it is in sub-sample $B$. This helps us uncover the structural parameters of the model without an instrumental variable. What the hypothesized difference in shocks in the two sub-samples means is that the scatter of observations in $(y, I)$ space in sub-sample $A$ is aligned more closely along the income equation (1) than it is in sub-sample $B$. In the limit, if the variance of $v$ is infinite in subsample $A$, the scatter of observations in that sub-sample would trace out the income equation (1) perfectly. More generally, as long as relative variances of the structural shocks differ across sub-samples, this difference provides us with a "probabilistic instrument", and allows us to solve the problem of identification.

Somewhat more formally, the reason that the system of equations (1)-(2) is not identified is that we need to estimate four unknowns, $\hat{\beta}, \hat{\theta}, \sigma_{\varepsilon}^{2}$, and $\sigma_{v}^{2}$ while the data yield estimates of only three moments, $\operatorname{var}(y), \operatorname{var}(I)$, and $\operatorname{cov}(y, I)$. Suppose now that we could split our data into two sub-samples $(j=A, B)$ with identical parameters $\beta$ and $\theta$, but different variances for the random shocks $\left(\sigma_{\varepsilon, A}^{2} \neq \sigma_{\varepsilon, B}^{2}\right.$ and $\left.\sigma_{v, A}^{2} \neq \sigma_{v, B}^{2}\right)$. The two subsamples now yield two separate variance-covariance matrices and six moments, which are enough to solve for the six unknowns $\left(\hat{\beta}, \hat{\theta}, \sigma_{\varepsilon, A}^{2}, \sigma_{\varepsilon, B}^{2}, \sigma_{v, A}^{2}, \sigma_{v, B}^{2}\right)$. In other words, splitting the sample adds two new unknowns (two additional variances), while generating three bits of useful information, and therefore identifies the system. Moreover, if our equations contain truly exogenous variables (such as distance from the equator), the system becomes over-identified. That in turn enables us to insert additional endogenous regressors. We shall describe our procedures in greater detail in the next section.

The IH method relies on two critical identification assumptions. First, the parameters of interest (i.e., $\beta$ and $\theta$ in the above example) are identical in the different sub-samples. We consider this particular assumption to be innocuous, since it has long been the maintained assumption in the cross-national literature, where it is standard practice to pool the data for all countries in the sample. The second, and more critical 
identifying assumption is that we can split the data into sub-samples with different relative variances of the structural shocks. This is where we need to rely on prior assumptions and make plausible guesses.

In this paper we use two different splits. First we distinguish between countries that have been colonized by European powers and countries that have not. While both sets of countries exhibit wide variance in income levels (RST 2002), the (unconditional) variance of incomes (and of other endogenous regressors) is typically larger in the noncolonized group than it is in the colonized group. Our maintained assumption here is that colonization is a homogenizing experience that reduces the variance of shocks to which countries have been subjected. Countries that have not been colonized by European powers have been open to a much wider array of influences and ruler types. Note that making this distinction between the two groups is not inconsistent with the assumption that the parameters of interest are stable across the two groups. Non-colonized countries may have had more heterogeneous outcomes in institutional arrangements (due to exogenous shocks), but that does not imply that the impact of institutions on incomes, or vice versa, is any different in that sample.

The second split we use relies on an argument made by Jared Diamond (1997) regarding how geography interacts with technology transfer. Diamond points out that it is easier for new seed varieties and other agricultural technologies to migrate on an EastWest axis than on a North-South axis. The reason is that moving in the North-South direction entails traversing different ecological and climatic zones, with attendant loss in the suitability and adaptability of agricultural innovations. Hence we split our sample between countries that are located in continents aligned on an East-West axis (Eurasian countries) versus those in continents aligned on a North-South axis (Africa and the Americas). Once again, the idea is that the relative magnitude of structural shocks will differ in the two samples without necessarily altering the parameters of interest. In particular, following Diamond we expect the variance of income shocks to be larger in the North-South sample than in the East-West sample.

One important feature of our methodology is that if both splits of the data are valid, then the coefficients should be the same across specifications. We perform this test and are unable to reject the overidentifying restrictions. Not only are the point estimates not statistically different, but our two splits produce remarkably similar coefficients. Finally, another advantage of our procedure is that because all the variances and coefficients are estimated we can compute a variance decomposition and evaluate the respective contributions of the explanatory variables to explaining the observed variance in outcomes.

We apply this approach to analyze the joint determination of four endogenous variables: incomes (GDP per capita), economic institutions (rule of law), political institutions (democracy), and integration (trade). Aside from these endogenous variables, our specifications include distance from the equator, population, and land area as exogenous regressors. Note that in contrast with the previous literature, we are able to 
estimate the impact of income levels on the other endogenous variables. Returning to the questions we posed at the opening of this paper, we find:

1. Democracy and the rule of law are both good for economic performance, but the latter has a much stronger impact on incomes (both statistically and quantitatively). Using the colony split, the estimated coefficient on rule of law is smaller than the OLS estimate-exactly as we would have expected in the presence of feedback from income.

2. Openness (trade/GDP) has a negative impact on income levels after we control for geography and institutions.

3. Countries located far from the equator are richer, although this effect is smaller when we use the geographical split. Interestingly, because distance to the equator has a sizable impact on our endogenous variables, it ends up explaining an important proportion of the variance in incomes. Using the colony/non-colony split, the proportion of the variance that is ultimately explained by distance from the equator is 20 percent.

4. Having a large land area or population is bad (in general) for economic performance. Even though the estimated coefficients for area are highly statistically significant, country size explains less than 7 percent of the variance in income.

5. Turning to the determinants of institutions, we find that higher income produces better institutions (but our estimates here are not terribly significant). This is true both for democracy and for rule of law. Income explains a little less than 10 percent of the variation in institutions.

6. Rule of law and democracy are generally mutually reinforcing and they tend to feed on each other. Greater rule of law produces more democracy, and vice versa. But the effects are not strong: the estimates are sometimes insignificant and in most cases they explain less than 10 percent of the variation.

7. Trade openness is good for the rule of law but bad for democracy. Trade's estimated (negative) impact on democracy is very significant, while its estimated (positive) impact on the rule of law is significant in one specification and insignificant in the other. The asymmetric effect of trade on economic and political institutions is one of our most striking findings. It is also a very robust result, surviving all the specifications we ran. Regarding the variance decomposition, however, openness contributes very little to the determination of institutions (less than 10 percent).

8. Distance from the equator has a significant effect on democracy and rule of law, and explains between 8 and 17 percent of the variation in democracy and between 22 and 40 percent of the variation of rule of law. 
9. Income has a positive but small impact on the degree of openness. Democracy and rule of law have negligible effects on openness. The variance decomposition indicates a very small explanatory power of institutions on openness (less than 2 percent).

10. Finally, the most important variables determining the degree of openness are those related to geography: distance from the equator, land area and population. Taken together, they explain more that 50 percent of the variation in openness in the sample.

These results are generally quite robust to changes in the underlying specifications and the use of one split versus the other. We estimated the same system of equations using two different splits, and various different measures of openness, democracy, and institutions. In all these estimations the coefficients turned out to be relatively stable. In comparing our preferred specification to the ones from the sensitivity analysis, we find that coefficients that are significant in the former usually are also significant in the latter, with the same sign. The few cases in which the coefficients reverse signs are those where the coefficients are badly estimated (with large standard errors). However, we never found a single case in which the hypothesis of parameter stability could be rejected.

The plan of the paper is as follows. Section II presents our methodology in greater detail. Section III presents and discusses the results. Section IV discusses robustness and other issues. Section V concludes.

\section{Solving the estimation problem}

One of the thorniest problems in applied work is the presence of simultaneousequations bias. As we discussed in the introduction, the coefficients in equations (1) and (2) cannot be consistently estimated without the help of instrumental variables, which requires us to locate exogenous variables that belong in one of the equations but not the other. In particular, to estimate the impact of institutions on income through instrumental variables necessitates that there exist a variable $(z)$ that is correlated with institutions but not with the innovation to the income equation:

$$
\begin{aligned}
& y=\beta I+\varepsilon \\
& I=\theta y+\gamma z+v
\end{aligned}
$$

This is an exclusion restriction that allows us to estimate the coefficient in the first equation $(\beta)$. However, there are several applications in which this assumption cannot be imposed, and hence there does not exist a plausible instrument that can solve the problem of estimation. Furthermore, IV allows us to estimate one equation (the income equation in this example) but does not help us estimate the other (the institutions equation). 
In this paper we use an alternative method-Identification through Heteroskedasticity (IH)-to deal with the simultaneous equations issues that are likely to be present in the joint determination of institutions, openness, and income. In this section we present the intuition of the procedure for a general multinomial system of equations assuming that all variables are endogenous. This is done to simplify the exposition. The more general case, including exogenous variables, is discussed below.

Assume that there is a set of $N$ endogenous variables denoted by $X$, and assume that the "true" model (which is known as the structural form) is denoted as

$$
A X=c+\varepsilon
$$

where the matrix $A$ is the matrix that characterizes the contemporaneous relationships among the endogenous variables. In general it is assumed that the diagonal of the matrix is equal to 1 (which is known as the normalization assumption). Our application is cross sectional and lags are not included in the specification. The constant terms are denoted by the vector $c$. The residuals $(\varepsilon)$ are known as the structural shocks and in most macroeconomic and development applications they are assumed to be uncorrelated. In other words:

$$
\operatorname{var}(\varepsilon)=\Sigma=\left[\begin{array}{cccc}
\sigma_{\varepsilon, 1}^{2} & 0 & \cdots & 0 \\
0 & \sigma_{\varepsilon, 2}^{2} & \cdots & 0 \\
\vdots & \vdots & \ddots & \vdots \\
0 & 0 & \cdots & \sigma_{\varepsilon, N}^{2}
\end{array}\right]
$$

The reduced form of the model is given by

$$
X=A^{-1} c+A^{-1} \mathcal{E}
$$

with the reduced form residuals defined as

$$
\eta=A^{-1} \varepsilon
$$

Although the structural form cannot be estimated, the reduced form can. In this particular case, we can estimate the reduced form constant terms and the covariance matrix of the reduced form residuals. In fact, these are the only statistics that can be obtained from the data.

The question of identification has to do with whether the structural coefficients can be recovered from the reduced form estimates. In general, the answer is no. For instance, the covariance matrix of the reduced form shocks is

$$
\operatorname{var}(X)=\operatorname{var}(\eta)=A^{-1} \Sigma A^{-1^{\prime}}
$$


Note that in a system with $N$ endogenous variables the matrix $A$ has $N^{2}$ terms, and the covariance matrix of the structural form residuals has $N$ terms-which accounts for a total of $N(N+1)$ unknowns. On the other hand, the covariance matrix of the reduced form residuals provides $\frac{N(N+1)}{2}$ equations-half of what is needed to solve the problem of estimation. This is indeed the standard problem of identification in simultaneous equations models. The number of reduced form coefficients-or moments that can be estimated from the reduced form-is smaller than the number of unknowns-or structural parameters.

The idea of identification through heteroskedasticity is to increase the number of available moments or equations such that the problem of identification can be solved. So let us assume that the sample can be split in two ( $s 1$ and $s 2)$ in a manner that satisfies the following properties:

$$
\begin{aligned}
& A X^{s 1}=c+\varepsilon^{s 1} \\
& A X^{s 2}=c+\varepsilon^{s 2} \\
& \operatorname{var}\left(\varepsilon^{s 1}\right)=\Sigma^{s 1} \\
& \operatorname{var}\left(\varepsilon^{s 2}\right)=\Sigma^{s 2} \\
& \Sigma^{s 1} \neq \Sigma^{s 2}
\end{aligned}
$$

This structure only adds the assumption that the data has heteroskedasticity. All other aspects of the structure remain identical. This model assumes that the constant $(c)$ and the set of coefficients on the endogenous matrix $(A)$ are the same across the crosssection. The only difference is in the variance of the residuals of the structural equations across the two sub-samples. This change implies that the reduced form covariance matrix of each sub-sample now provides $\frac{N(N+1)}{2}$ equations. The order condition requires that the number of knowns be larger than or equal to the number of unknowns. The rank condition specifies that the knowns (or equations) have to be linearly independent. In standard linear systems of equations we test for the rank condition given that the order condition is satisfied. In other words, we count the number of equations and the number of unknowns. If the number of equations is larger than the unknowns we compute the rank of the matrix of the system. If that rank is larger than the number of unknowns then the system of equations has at least as many linearly independent equations as the number of unknowns; and therefore there is a solution.

In our case this is exactly what we can do. We assume the heteroskedasticity in the data, and count whether or not there are more moments in the data than the number of coefficients that have to be estimated. Assuming that such a condition is satisfied, then we can proceed and test if the estimates of the structural equation variances are different across sub-samples-which is equivalent to the rank condition. 
It is important to highlight the identifying assumption in this procedure - the fact that the structural shocks are uncorrelated. If the shocks were correlated and there is no restriction on the variation of such covariance, then every heteroskedastic regime adds as many equations as unknowns, and the problem of identification could not be solved. Observe that there is a crucial difference between parameter stability and the covariance assumption. Parameter stability can be tested if there is enough regimes. The reason is that it can be estimated assuming that parameters are stable and check the overidentifying restrictions. The zero correlation assumption, on the other hand, cannot be tested. This is the identifying assumption, and therefore it is maintained. In our application, given that we are including income, institutional variables, openness, and geographical variables we believe that we are considering enough variables such that no additional variables are needed.

Finally, it should be obvious that heteroskedasticity can be combined with other assumptions (such as exclusion restrictions), in which case the system of equations will become overidentified. In our application, several of the variables in $X$ can be considered exogenous (for example, geographical variables), and therefore, the problem of identification can be lessened.

The literature on identification through heteroskedasticity is based on the original intuition provided by Philip Wright (1928). Wright indicates that we can solve the problem of identification if instead of moving the mean (which is the standard IV methodology) we find a variable that increases the variance of one of the equations to infinity. In other words, if the volatility of the innovations to the demand schedule is infinitely large in comparison to the volatility of the innovations in the supply schedule, effectively we only observe movements due to innovations to the demand, and therefore we can estimate the supply schedule directly. This is known today as "near identification" (Fisher 1976).

Recently this methodology has been revisited and extended to time series and panel data. The most important innovation of this new literature is that the original intuition of taking the variance to infinity has been shown to be not required. It is enough to find a shift in the variances of the structural shocks that changes their relative importance. Leamer (1981) pointed out in the standard supply and demand framework that the admissible coefficients belong to a hyperbola. If the variances of the shocks shift, then the hyperbola rotates and the pivotal point is the pair of true coefficients. See Rigobon (2003) and Lewbel (2004) for the formal derivation. ${ }^{4}$

\footnotetext{
${ }^{4}$ Regarding the development of the theory in the times series literature see Sentana (1992), Sentana and Fiorentini (2001), and Rigobon (2003a). For applications see in Caporale, et. al. (2002a), Rigobon (2002a), Rigobon and Sack (2003a). In these papers the heteroskedasticity is modeled as a GARCH process and the authors use the heteroskedasticity in the time series mainly as a statistical method to achieve identification. See Rigobon (2002b 2003b), Rigobon and Sack (2003b), Caporale teal. (2002b) for applications where the heteroskedasticity is described by regime shifts. In these papers economic events are used to determine the regimes. Additionally, see Rigobon and Sack (2002) and Evans and Lyons (2003) for applications of the identification through heteroskedasticity to event study estimation. Few applications have been applied to panel data in the literature. Hogan and Rigobon (2003) apply the method to a very large panel data to estimate the returns to education, where the regions of the UK are used as the different regimes. Klein and
} 


\section{Results}

In this section we apply the methodology described above to our problem. We are interested in estimating the relationships among income, political institutions (democracy), economic institutions (rule of law), openness, distance from the equator, land area, and population. ${ }^{5} \mathrm{We}$ assume that the last three are exogenous to the first four allowing us to have a large set of overidentifying restrictions. So our system includes four endogenous variables (income, democracy, rule of law, openness) and three exogenous variables (distance from equator, area, population). We allow the equation for each of the endogenous variables to include all the exogenous variables as well as the (other) endogenous variables.

The data come from the standard sources: Penn World Tables and World Development Indicators for economic data, Polity IV for indicators of democracy and constraint on the executive, and Knack and Keefer (1995) and Kaufmann et al. (2002) for the rule of law.

Table 1 shows the summary statistics of the variables included in most of the specifications.

Table 1: Summary Statistics

Distance from the Equator
Country Area
Openness
Population
Openness (PWT)
GDP percapita
Democracy
Constraints on the executive
Rule of Law (Kaufmann et al.)
Rule of Law 80 s (KK)
Rule of Law 90s (KK)

$\begin{array}{lccc} & \text { Num Obs. } & \text { Average } & \text { Std. Deviation } \\ \text { disteq } & 208 & 25.0 & 16.8 \\ \text { area } & 162 & 315534.2 & 902546.9 \\ \text { copen } & 170 & 72.9 & 43.6 \\ \text { pop } & 192 & 29.3 & 113.2 \\ \text { pwtopen } & 171 & 74.0 & 42.7 \\ \text { gdppc } & 165 & 7358.9 & 7541.9 \\ \text { democ } & 161 & 0.5 & 19.1 \\ \text { xconst } & 161 & 0.1 & 18.7 \\ \text { rulelawkkz } & 81 & -0.3 & 0.9 \\ \text { rulelaw80 } & 126 & 3.1 & 1.5 \\ \text { rulelaw90 } & 131 & 3.8 & 1.3\end{array}$

Vella (2003) also use heteroskedasticity to estimate the returns to education. They use a nonparametric model to describe the heteroskedasticity as a function of the regressors. Broda and Weinstein (2003) use the inequality constraints together with the heteroskedasticity to estimate the elasticities of substitution in models of trade to evaluate the gains from variety in the same spirit of Leamer's (1981). Pattillo, Poirson, and Ricci (2003) use the IH method to identify the impact of external debt on growth. Hviding and Ricci (2003) investigate the impact of official reserves on exchange rate volatility. These last two papers use the regime shift methodology of times series to obtain the different groups in the population.

${ }^{5} \mathrm{We}$ include land area and population primarily because these have been frequently used as determinants of openness. Frankel and Romer (1999) argue that these also belong in the income equation when openness is used as a determinant. 
One important ingredient in the identification strategy (IH) is the split of the data in several groups. We assume that there are two groups in the sample in terms of their variances of the structural shocks. The assumption that the same $A$ applies to both subsamples is innocuous, insofar as it is an implicit assumption made whenever we estimate the system by OLS or IV by pooling the two sub-samples. We use two criteria to split our sample in two different ways. First, we distinguish between countries that were colonized by Europeans and countries that were not. We rely here on the argument that colonization has been, relatively speaking, a homogenizing experience insofar as it has implied rule by a few metropolitan centers and the adoption of practices and institutions imposed from these centers. Everything else being the same, this historical experience should have reduced the variance of the structural shocks to which colonized countries have been subjected to, compared to non-colonized countries. Countries that have been occupied by Europeans for a relatively short period of time (fewer than 25 years) are not included in the colonized group. ${ }^{6}$ Second, we split the data according to the way the continents are aligned, distinguishing between horizontal and vertical continents. Here we rely on an argument made by Jared Diamond (1997) regarding how geography interacts with technology transfer. Diamond points out that it is easier for new seed varieties and other agricultural technologies to migrate on an East-West axis than on a North-South axis. The reason is that moving in the North-South direction entails traversing different ecological and climatic zones, with attendant loss in the suitability and adaptability of agricultural innovations. Hence we split our sample between countries that are located in continents aligned on an East-West axis (Eurasian countries) versus those in continents aligned on a North-South axis (Africa and the Americas).

In the appendix we present the list of countries in each of the splits. Under the colony split we have 70 countries that have not being colonized by Europeans for a significant period of time, and 168 countries that have been. We do not have information about institutions, openness, etc. for all of them and the final sample constitutes 53 colonized countries and 33 not colonized countries. The geographical orientation split has fewer countries in the sample (Oceania is excluded). We have 98 countries that belong to continents that are horizontally aligned (Eurasia) and 59 countries in continents that are vertically aligned (Africa and the Americas). The final sample with all the data contains 43 countries in each sub-sample.

\section{III.1 Openness, institutions, and income with OLS}

As a first step, we show the results when the income equation is estimated using OLS without instruments. We estimate the following specification:

\footnotetext{
${ }^{6}$ Our variable requires that the colonization take place before the beginning of the $20^{\text {th }}$ century, and that the country be occupied for more than 25 years. We have also employed an alternative colonization variable that is set to one if Europeans colonized the country for short periods of time, at any time before world war one. The results are almost unaffected by the change in the split and therefore are not presented. These results are available upon request.
} 


$$
y=\alpha_{1} \text { idem }+\alpha_{2} \text { irol }+\alpha_{3} \text { open }+\alpha_{4} \text { disteq }+\alpha_{5} \text { area }+\alpha_{6} \text { pop }
$$

where $y$, idem, irol, open, disteq, area, and pop are log output, democratic institutions, economic institutions (rule of law), log of openness (trade/GDP), distance from the equator (which is divided by 100), log of area, and log of population. This is the benchmark to which our estimates are going to be compared. We normalize each variable by its standard deviation in the whole sample to facilitate evaluation of the quantitative significance of the estimated coefficients.

The results of estimating the OLS on the full equation are summarized in Table 2 ( $t$-statistics are reported under the coefficient estimates).

Table 2: Income Equation: OLS estimates

$\begin{array}{ccccccc} & \text { Idem } & \text { Irol } & \text { Open } & \text { DistEq } & \text { Area } & \text { Pop } \\ \text { y } & 0.187 & 0.539 & 0.035 & 0.185 & 0.185 & -0.151 \\ & 2.3 & 5.4 & 0.3 & 2.0 & 2.0 & -1.8\end{array}$

The first coefficient indicates that an improvement in democratic institutions improves income significantly. The second estimate shows that an improvement in economic institutions - measured by the rule of law - also increases the income level, with a larger impact than democratic institutions. In this regression openness is not significant. This result appears when in the OLS regression several measures of institutions are included in the specification. Regarding the effect of geography, distance from the equator is associated with an improvement in the income levels, larger countries have higher incomes, and countries with large populations have smaller income levels (this last one is only marginally significant).

Instrumental variables versions of such a specification have been reported in work by AJR (2001), FR (1999), Easterly and Levine (2003), RST (2002), Dollar and Kraay (2002), Alcala and Ciccone (2003), and Sachs (2003). Generally, these results point to an important causal impact of institutional quality, with all studies that have explicitly considered the role of institutions finding a strong effect. But the causal role played by trade and geography still remains controversial. For example, RST (2002) finds no significant role for trade once institutional quality is controlled, and AJR (2001), Easterly and Levine (2003), and RST (2002) find only an indirect effect of geography (through institutional quality).

As we discussed earlier, IV estimates are subject to questions having to do with the plausibility and quality of the instruments selected. Moreover, none of these earlier studies is able to distinguish between economic and political institutions, and none can examine the full set of interactions among the endogenous variables. That is where the advantages of the current approach lie.

\section{III.2 IH estimation}

Our approach identifies the relationship among the endogenous variables not through instrumentation but by appealing to heteroskedasticity in the data. Because 
several of the variables under analysis (all the geography ones) are exogenous to income, institutions, and openness, we can impose some exclusion restrictions on the system. These improve the estimation, and can be used to test for overidentifying restrictions. In particular, we assume that the model takes the following form:

$$
\underbrace{\left[\begin{array}{ccccccc}
1 & a_{12} & a_{13} & a_{14} & a_{15} & a_{16} & a_{17} \\
a_{21} & 1 & a_{23} & a_{24} & a_{25} & a_{26} & a_{27} \\
a_{31} & a_{32} & 1 & a_{34} & a_{35} & a_{36} & a_{37} \\
a_{41} & a_{42} & a_{43} & 1 & a_{45} & a_{46} & a_{47} \\
0 & 0 & 0 & 0 & 1 & 0 & 0 \\
0 & 0 & 0 & 0 & a_{65} & 1 & 0 \\
0 & 0 & 0 & 0 & a_{75} & a_{76} & 1
\end{array}\right]}_{A}\left[\begin{array}{c}
y \\
\text { idem } \\
\text { irol } \\
\text { open } \\
\text { disteq } \\
\text { area } \\
\text { pop }
\end{array}\right]=\left[\begin{array}{c}
c_{y} \\
c_{\text {idem }} \\
c_{\text {irol }} \\
c_{\text {open }} \\
c_{\text {disteq }} \\
c_{\text {area }} \\
c_{\text {pop }}
\end{array}\right]+\left[\begin{array}{c}
\varepsilon_{y} \\
\varepsilon_{\text {idem }} \\
\varepsilon_{\text {irol }} \\
\varepsilon_{\text {open }} \\
\varepsilon_{\text {disteq }} \\
\varepsilon_{\text {area }} \\
\varepsilon_{\text {pop }}
\end{array}\right]
$$

where the pre-multiplying matrix is $A$, and where as before $y$, idem, irol, open, disteq, area, and pop denote output, democratic institutions, economic institutions (rule of law), openness, distance to the equator, area, and population, respectively. In the estimation we allow for different constant terms across the splits in the data.

As in the simple example, we assume that the covariance of the structural residuals is diagonal; in other words, these residuals truly reflect independent innovations to each of the observed variables. Observe that in matrix $A$ we have imposed the assumption that distance, area, and population are exogenous to income, institutions, and openness-the coefficients of the lower-matrix $a_{51}$ to $a_{74}$ are all set equal to zero. Moreover, we allow interrelationships among these three exogenous variables through the coefficients $a_{65}, a_{75}$, and $a_{76}$, but with the assumption that distance from the equator is the most exogenous one, and population the least exogenous. In other words, we allow population to be a function of distance from equator and area, and area to be a function of distance from equator.

As was mentioned before we use two splits to estimate the model using the heteroskedasticity across the sub-samples. Both splits assume that the differences across groups are concentrated on their second moments and not on their $A$-matrix coefficients. In other words, our assumption is that the variances change but the coefficients in matrix $A$ do not. One advantage of the $\mathrm{IH}$ methodology is that the parameter stability assumption can be tested. In our particular application this is best done by comparing the estimates from the different splits of the data.

The parameters of interest are the endogenous coefficients (matrix $A$ ), the structural variances in each of the regimes, and the intercepts. All of our estimation is performed by GMM, and the iteration process for convergence is as follows: 
1. Given the parameters (matrix $A$, the structural variances, and intercepts) We compute the structural residuals in each regime

$\eta_{i}=A \times[y$ idem irol open disteq area pop $]$

2. The identifying assumption is that the covariance terms of the structural shocks are zero. We compute these moment conditions for each regime and each pair of variables.

3. Finally, we minimize the moment conditions searching for the intercepts, variances and contemporaneous coefficients.

Note that in the construction of the moments we are conditioning on the split (this is not estimated, but assumed). An alternative would be to assume that countries belong to two different types differentiated only by their standard deviation. We could estimate that model where we do not have to commit to any ex-ante split of the data. This procedure would use the heteroskedasticity in the data as statistical means to solve the problem of identification. Although a significant part of the literature using heteroskedasticity - specially the one in which ARCH and GARCH models are fitted - is along this line, we believe that using an economic reason behind the identification has several advantages: First, we understand what the split is achieving and why. Second, because we have economic reasons to believe that the split changes the second moments but not the first moments or the contemporaneous coefficients we feel more comfortable with the outcome of the methodology and the assumption that the parameters are stable. Finally, using economic reasoning to construct the split, instead of random differences, eliminates some of the mysterious aspect of the identification.

The first question that arises is how different are the two sub-samples under these splits? Are the means statistically different? Are the second moments? The following two tables answer these questions. Table 3 shows the estimated constant terms ( $c$ 's) - the structural intercepts - derived using the GMM procedure.

Table 3: Differences in means across sub-samples

\begin{tabular}{|c|c|c|c|c|c|c|c|c|c|c|c|c|c|c|c|}
\hline & & \multicolumn{2}{|c|}{ Y } & \multicolumn{2}{|c|}{ Idem } & \multicolumn{2}{|c|}{ Irol } & \multicolumn{2}{|c|}{ Open } & \multicolumn{2}{|c|}{ DistEq } & \multicolumn{2}{|c|}{ Area } & \multicolumn{2}{|c|}{ Pop } \\
\hline & & s1 & $\mathrm{s} 2$ & s1 & $\mathrm{s} 2$ & s1 & $\mathrm{s} 2$ & s1 & S2 & s1 & $\mathrm{s} 2$ & s1 & s2 & $\mathrm{S} 1$ & $\mathrm{~s} 2$ \\
\hline \multirow[t]{3}{*}{ Colony } & Mean & 5.30 & 5.20 & 1.28 & 1.42 & -5.1 & -5.1 & 14.67 & 14.77 & 1.01 & 2.52 & 6.30 & 5.28 & 7.01 & 7.54 \\
\hline & StDev & 1.72 & 1.73 & 2.25 & 2.26 & 2.01 & 2.03 & 0.96 & 0.98 & 0.09 & 0.12 & 0.22 & 0.46 & 0.60 & 0.58 \\
\hline & & & 0.04 & & 0.05 & & 0.01 & & 0.07 & & 9.99 & & 2.01 & & 0.63 \\
\hline \multirow{3}{*}{$\begin{array}{l}\text { Geog. } \\
\text { orientation }\end{array}$} & Mean & 5.99 & 5.81 & 4.07 & 4.01 & -6.2 & -6.0 & 15.71 & 15.15 & 2.22 & 0.95 & 5.61 & 6.43 & 7.39 & 6.51 \\
\hline & StDev & 1.90 & 1.81 & 2.50 & 2.41 & 2.29 & 2.18 & 0.97 & 0.92 & 0.14 & 0.10 & 0.35 & 0.19 & 0.50 & 0.52 \\
\hline & & & 0.07 & & 0.02 & & 0.06 & & 0.42 & & 7.64 & & 2.04 & & 1.22 \\
\hline
\end{tabular}

For each split and variable, the first entry is the mean in sub-sample one (s1) and the second entry is the mean in the other sub-sample (s2). Below each mean we show the standard deviation of the mean and the t-statistic associated with the test for the equality of the means. As can be seen, the two sub-samples reveal no differences in means with respect to our four endogenous variables--income, democracy, rule of law, and openness. This result holds for both of our splits. Any significant difference in means across sub- 
samples is confined to some of our exogenous variables (distance from the equator and land area).

Our methodology relies on the assumption that second moments are statistically different across the sub-samples generated by our splits. In Table 4 we show the differences in the variances of all seven variables across the sub-samples. As before, these are the variances of the structural shocks after the model has been estimated using GMM. Remember that the identification requires heteroskedasticity of the structural shocks and not of the reduced form shocks.

As before, the first row for each split is the estimated standard deviation of the variable of interest; the second row is the standard deviation of this estimate; and the last row is the standard t-test for equality between the latter standard deviations. As can be seen, there are important differences here. In about half of the cases the standard deviations across the two sub-samples are statistically different. It is this feature of the data that enables us to estimate the coefficients using heteroskedasticity. If it were the case that second moments are not statistically different across splits identification would remain a hopeless task.

\begin{tabular}{|c|c|c|c|c|c|c|c|c|c|c|c|c|c|c|c|}
\hline & & \multicolumn{2}{|c|}{$\mathrm{Y}$} & \multicolumn{2}{|c|}{ Idem } & \multicolumn{2}{|c|}{ Irol } & \multicolumn{2}{|c|}{ Open } & \multicolumn{2}{|c|}{ DistEq } & \multicolumn{2}{|c|}{ Area } & \multicolumn{2}{|c|}{ Pop } \\
\hline & & s1 & s2 & s1 & $\mathrm{s} 2$ & s1 & $\mathrm{s} 2$ & s1 & $\mathrm{s} 2$ & $\mathrm{~s} 1$ & s2 & s1 & s2 & $\mathrm{s} 1$ & s2 \\
\hline \multirow[t]{3}{*}{ Colony } & $\sigma$ & 0.49 & 0.18 & 0.79 & 0.21 & 0.45 & 0.42 & 0.36 & 0.34 & 0.44 & 0.47 & 0.94 & 0.71 & 0.60 & 0.58 \\
\hline & StDev & 0.10 & 0.05 & 0.16 & 0.06 & 0.09 & 0.11 & 0.07 & 0.09 & 0.09 & 0.12 & 0.20 & 0.19 & 0.12 & 0.15 \\
\hline & & & 2.74 & & 3.36 & & 0.24 & & 0.12 & & 0.20 & & 0.84 & & 0.10 \\
\hline \multirow{3}{*}{$\begin{array}{l}\text { Geog. } \\
\text { orientation }\end{array}$} & $\sigma$ & 0.19 & 0.56 & 0.34 & 0.78 & 0.37 & 0.51 & 0.32 & 0.31 & 0.78 & 0.39 & 0.96 & 0.83 & 0.66 & 0.34 \\
\hline & StDev & 0.04 & 0.13 & 0.08 & 0.18 & 0.09 & 0.13 & 0.07 & 0.07 & 0.17 & 0.08 & 0.21 & 0.19 & 0.15 & 0.08 \\
\hline & & & 2.69 & & 2.24 & & 0.93 & & 0.10 & & 2.07 & & 0.43 & & 1.91 \\
\hline
\end{tabular}

The results when the data are organized according to the geography split (shown in the bottom panel in each table) produce very similar results regarding means and standard deviations. In general, there are no large differences in the means, but significant disparities in second moments.

We are now ready to discuss the results of interest. The estimates of matrix $A$ using the colony variable to split the data are shown in Table 5; the estimates using geographical orientation are shown in Table 6.

Table 5: Estimates of $\boldsymbol{A}$ matrix: Colony split

$\begin{array}{lccccccc} & \mathrm{Y} & \text { Idem } & \text { Irol } & \text { Open } & \text { DistEq } & \text { Area } & \text { Pop } \\ \text { Income } & & 0.233 & 0.243 & -0.360 & 0.245 & -0.209 & -0.105 \\ & & 1.64 & 1.88 & 4.02 & 2.38 & 3.68 & 1.57 \\ \text { Democracy } & 0.433 & & -0.392 & -0.294 & 0.267 & -0.175 & -0.179 \\ & 1.04 & & 0.88 & 2.24 & 1.96 & 1.70 & 2.51 \\ \text { Rule of Law } & 0.198 & 0.432 & & 0.316 & 0.228 & 0.146 & 0.086 \\ & 1.69 & 2.96 & & 3.40 & 1.91 & 1.84 & 1.27 \\ \text { Openness } & 0.452 & 0.009 & -0.052 & & -0.274 & -0.138 & -0.550\end{array}$


$\begin{array}{llllll}2.60 & 0.07 & 0.19 & 1.82 & 2.35 & 8.21\end{array}$

Table 6: Estimates of $\boldsymbol{A}$ matrix: Geographical orientation split

$\begin{array}{lccccccc} & Y & \text { Idem } & \text { Irol } & \text { Open } & \text { DistEq } & \text { Area } & \text { Pop } \\ \text { Income } & & 0.034 & 0.739 & -0.179 & -0.014 & -0.235 & 0.065 \\ & & 0.32 & 9.89 & 2.03 & 0.19 & 3.17 & 1.03 \\ \text { Democracy } & 0.145 & & 0.254 & -0.358 & 0.121 & 0.068 & -0.460 \\ & 0.61 & & 1.60 & 2.47 & 0.89 & 0.85 & 4.57 \\ \text { Rule of Law } & 0.129 & 0.099 & & 0.177 & 0.720 & -0.127 & 0.057 \\ & 0.78 & 0.58 & & 1.21 & 4.06 & 2.53 & 0.54 \\ \text { Openness } & 0.033 & -0.034 & 0.035 & & -0.127 & -0.081 & -0.677 \\ & 0.26 & 0.27 & 0.26 & & 0.93 & 1.19 & 11.20\end{array}$

In both Tables we present only the equations for income, democracy, rule of law, and openness. The equations for distance from the equator, area, and population are not presented as they are not of interest. Each table is organized as follows: The first equation is the income equation, which is a function of the other six variables. Each entry presents the point estimate and the t-stat. The coefficients in the table are the coefficients of the matrix multiplied by -1 , so, they have the same signs as if we had run them on the right hand side, instead of on the left hand side. This is just for ease of presentation of the results and to simplify the discussion and comparison between these estimates and those form OLS. The second equation shows the determination of democratic institutions as a function of the other six variables, and so forth. All the variables have been normalized by their standard deviations and therefore the point estimates are comparable and have the same interpretation as those from Table 2.

Before proceeding to interpret each equation it is important to point out the stability of the coefficients across the two splits of the data. Remember that the set of countries included in one of the splits is different from that included in the other. Hence, the grouping cuts the data from two very different perspectives, and still the estimates are close-not only statistically but also in magnitude. We can see this in a number of ways.

First, statistically speaking, we cannot reject the hypothesis that all the coefficient estimates are the same across the two splits; the F-test has a p-value of 0.14. Second, notice that the signs of the coefficients across the two tables are relatively consistent. For example, except for the non-significant coefficients the signs always agree across the two specifications. Third, the coefficients that are significant in one split are likely to be significant in the other or to be insignificant but of the same sign. For instance, in the first split there are 14 coefficients that are significant or borderline significant (t-stats larger than 1.80). From these coefficients, 6 have the same sign and are also significant in the second split, and only one has a different sign. That last coefficient is badly estimated and hence it is not statistically different from the coefficient estimated with the first split. Finally, the point estimates are close coefficient by coefficient. This strong robustness of the coefficient will be further highlighted below when we return to the sensitivity analysis, but as can be seen, the results seem to be quite robust so far.

We proceed equation by equation for the interpretation of the coefficients. The first equation in both tables summarizes the determinants of income. We find, in line with 
the existing literature, that the rule of law has a strong positive effect on income (although the estimated coefficient is only borderline significant with the colony split). Distance from the equator has a positive and significant effect in the first split, but an insignificant effect in the second split. Area and population enter significantly, although they have different signs from the OLS regressions - in fact, these coefficients are statistically different from those reported in Table 2 . Trade openness has a significant and negative effect on incomes in both splits. Note, however, that the estimated coefficient on openness is not statistically different from that in the OLS specification, mainly because the OLS coefficient is badly estimated. When only one of the two types of institutions is included in the OLS regression openness becomes significant, but when both are included the effect of openness disappears. So, the small effect is in part due to an aspect that has not been analyzed in the literature before. Finally, democracy enters with a positive sign in the income equation, but is (borderline) significant only with the colony split.

A standard result in the literature on institutions is that the estimated coefficient on institutions typically increases significantly when the income equation is estimated using IV rather than OLS (with settler mortality as an instrument for example). One explanation for this is the presence of errors-in-variables, which the instrumentation presumably corrects. Certainly this is a possibility; however, another potential reason for the IV coefficient to be larger than the OLS coefficient is that the instrument is invalid i.e., that settler mortality enters the income equation directly.

We cannot directly compare our results with the standard IV results because the literature using mortality as instrument only includes one type of institution (rule or law or a measure of expropriation) and we use two. Therefore, just for this discussion we reestimated the model eliminating the democracy variable. First, the OLS estimates are:

$\begin{array}{cccccc} & \text { Irol } & \text { Open } & \text { DistEq } & \text { Area } & \text { Pop } \\ \text { y } & 0.374 & 0.074 & 0.447 & -0.211 & 0.105 \\ & 4.80 & 0.74 & 5.78 & 2.22 & 1.09\end{array}$

This shows the usual result in the growth literature - the significant impact of rule of law and distance from the equator in explaining income differences in OLS specifications. If we apply the IH estimator to this data using the colony split, the results are as follows:

$\begin{array}{lcccccc} & \mathrm{Y} & \text { Irol } & \text { Open } & \text { DistEq } & \text { Area } & \text { Pop } \\ \text { Income } & & 0.161 & 0.321 & 0.528 & -0.085 & 0.185 \\ & & 2.14 & 1.98 & 8.10 & 1.44 & 2.00 \\ \text { Rule of Law } & 0.136 & & 0.064 & 0.509 & 0.155 & -0.150 \\ & 1.18 & & 0.46 & 6.10 & 2.07 & 1.93 \\ \text { Openness } & -0.148 & 0.152 & & -0.023 & -0.432 & -0.396 \\ & 0.95 & 1.54 & & 0.24 & 6.96 & 9.60\end{array}$

Notice that the coefficient on the rule of law is statistically significant, but it is half of the OLS estimate. Also observe that the feedback coefficient (income on rule of law) is positive and hence the OLS coefficient should be biased upwards. 
We now turn our attention to the determinants of the democratic institutions. Although some of the results in the income equation are known, very little work has been done to ascertain empirically how institutions are affected by income, the degree of openness, etc. We find that income has a positive (but statistically insignificant) effect on democratic institutions. We find that rule of law has a (marginally) significant coefficient in the democracy equation when the geography split is used, but this coefficient is negative and not significant when the colony split is used. There is a belief in the literature that institutions of different kinds reinforce each other and some of our results are suggestive of that. Third, and most strikingly, we find that openness is bad for democracy. This result is robust to the split (and even to changes in the definition of openness and of democratic institutions, as we discuss below). The effects are large and statistically significant. Distance from the equator has a positive impact on democratic institutions, although the effect is significant in only one of the specifications. The size of the country (measured as its area) has no impact on the quality of its democracy, while countries with larger populations are less democratic on average. This last effect is highly significant.

The results in the rule of law equation show some differences. On the one hand, income improves the quality of rule of law in the same way as it does for democracy although here the point estimate is larger and more significant. Additionally, better democracy improves the rule of law. The feedback effects in this case are larger and more significant than in the case of the impact of the rule of law on democratic institutions. Again, as we mentioned before, our methodology seems to be capturing the positive feedback between the quality of economic and political institutions. The main difference here is that in contrast to the case with democracy, openness improves the rule of law. The latter estimates are positive and significant in the first split, and just positive when the geography split is used. Putting these results together with the ones from the democracy equation we conclude that openness is working through institutions in two different ways. Countries that are more open tend to acquire better economic institutions, perhaps because this is required to better compete internationally. However, openness in general tends to weaken democratic institutions, perhaps because openness exacerbates distributional conflicts. This result also may help resolve some of the different findings found in the literature. If only one of the two institutions is included in an OLS equation for income, then the bias on the openness coefficient can go in either direction (considering that both institutions have positive impact on income).

Distance to the equator has a positive and significant effect on the quality of rule of law. In the case of the geography split this effect is large economically speaking. Regarding population and area, the message seems to be that larger countries seem to have worse quality of the rule of law, although the overall effect is small.

The openness equation reveals that the most important determinant of the degree of openness is income and geography. The level of income per capita has a positive impact on the degree of openness when the colony split is used, but it is insignificant in the other specification. Better democratic institutions or rule of law have a negligible 
impact on openness. Distance from the equator, area, and population have negative and significant effects on the degree of openness. Bigger countries are in general less open, and the closer they are to the equator the larger the share of trade.

One of the advantages of our procedure is that we can perform a variance decomposition, and determine the relative importance of each of the shocks. Given the estimates of matrix $A$, the structural residuals can be computed and the unconditional variance can be estimated from the sample:

$$
\operatorname{var}(\varepsilon)=\operatorname{var}(A X)
$$

The diagonal of this matrix is an estimate of the unconditional variance of the structural shocks. Given that variance we can compute the contribution of each shock to the variance of the observed variables. Denote

$$
B=\operatorname{inv}(A)=\left\lfloor b_{i j}\right\rfloor
$$

the elements of the inverse of $A$, and denote as $\sigma_{y}, \sigma_{\text {idem }}, \sigma_{\text {irol }}, \sigma_{\text {open }}, \sigma_{\text {DistEa }}, \sigma_{\text {area }}$, and $\sigma_{p o p}$ the unconditional variances of the structural residuals. Then the variance of variable $i$ (let us say income) is given

$$
\operatorname{var}\left(X_{i}\right)=\left(b_{i 1}\right)^{2} \sigma_{y}+\left(b_{i 2}\right)^{2} \sigma_{\text {idem }}+\left(b_{i 3}\right)^{2} \sigma_{\text {irol }}+\left(b_{i 4}\right)^{2} \sigma_{\text {open }}+\left(b_{i 5}\right)^{2} \sigma_{\text {DistEq }}+\left(b_{i 6}\right)^{2} \sigma_{\text {area }}+\left(b_{i 7}\right)^{2} \sigma_{\text {pop }}
$$

In this variance decomposition we are already assuming that the structural shocks are uncorrelated. In Table 7 we show the variance decomposition implied by the colony split, and in Table 8 we present the variance decomposition when the geography split is used.

Table 7: Variance decomposition: Colony split

$\begin{array}{lccccccc} & \text { Y } & \text { Idem } & \text { Irol } & \text { Open } & \text { DistEq } & \text { Area } & \text { Pop } \\ \text { Income } & 58.1 \% & 8.1 \% & 1.1 \% & 9.9 \% & 20.1 \% & 2.2 \% & 0.4 \% \\ \text { Democracy } & 1.2 \% & 73.3 \% & 4.1 \% & 10.2 \% & 8.0 \% & 3.2 \% & 0.0 \% \\ \text { Rule of Law } & 9.6 \% & 23.6 \% & 43.4 \% & 0.0 \% & 22.4 \% & 0.7 \% & 0.2 \% \\ \text { Openness } & 8.2 \% & 0.9 \% & 0.0 \% & 33.3 \% & 3.7 \% & 36.8 \% & 17.1 \%\end{array}$

Table 8: Variance decomposition: Geographical orientation split

$\begin{array}{lccccccc} & \mathrm{Y} & \text { Idem } & \text { Irol } & \text { Open } & \text { DistEq } & \text { Area } & \text { Pop } \\ \text { Income } & 38.6 \% & 0.8 \% & 31.3 \% & 0.3 \% & 21.4 \% & 6.6 \% & 0.9 \% \\ \text { Democracy } & 0.4 \% & 66.9 \% & 5.4 \% & 5.1 \% & 17.4 \% & 1.4 \% & 3.5 \% \\ \text { Rule of Law } & 0.4 \% & 0.5 \% & 49.8 \% & 1.2 \% & 44.3 \% & 3.1 \% & 0.7 \% \\ \text { Openness } & 0.0 \% & 0.0 \% & 0.1 \% & 43.7 \% & 0.9 \% & 27.1 \% & 28.1 \%\end{array}$

The interpretation of these results is as follows. Again, let us concentrate equation by equation. In the income equation, innovations to income uncorrelated with the any of 
the other residuals explain 58 and 39 percent of the variance depending on the specification. In other words, geography and institutions explain roughly 40 to 60 percent of the income variation we observe today. The two measures of institutions contribute from 9 to 32 percent of the variation of income while distance to the equator explains a little more than 20 percent. Indeed, all the geographic variables together explain less than 30 percent of the variation.

Regarding democratic institutions 70 percent of the variation is unexplained - or explained by own innovations. Rule of law explains only 5 percent of the variation, while openness explains a little more (almost 10 percent in the colony split). Distance to the equator has a larger effect, while area and population explain almost nothing.

Rule of law, on the other hand, is much better explained by the explanatory variables. Democracy and distance from the equator explain more than 40 percent of the variation, while area, population and income explain an additional 10 percent.

Finally, openness is also well explained by the explanatory variables. Only 33 to 43 percent of the variation is explained by innovations to openness alone. Interestingly, income and institutions have small explanatory power on openness and it is the geographical characteristics that are the most important determinants.

\section{Discussion}

\section{IV.1 Robustness}

The results we presented have been subjected to several sensitivity tests. First, we have substituted the variable "constraints on the executive" for democracy without major changes in the results. Second, we have also tried several definitions for rule of law. When we use the rule of law measures from Political Risk Services (Knack and Keefer 1995) averaged for the 1980s and 1990s, respectively, the results are almost identical. Third, we tried several standard measures of openness. When openness from the Penn World Tables is used (instead of the WDI measure) the estimates become less significant but the signs remain the same as those presented here. Finally, we also modified the definition of colonization including as "colonized" those countries where there was any presence of Europeans. The results are almost identical. Therefore, our findings are generally robust to redefinitions of the variables, exclusion of some countries, and changes in the split. The general message (signs and significance of the relationship) survived this sensitivity exercise.

\section{IV.2 Testing the model}

Even though the model is overidentified and therefore we can either test the overidentification or allow some coefficients to change across the sub-sample, it is important to understand that not all coefficients are overidentified. 
In particular, the overidentified coefficients in our model are those in the distance from the equator, area, and population equations (the exogenous variables); the other coefficients are just identified. Consequently, our test of overidentification is confined to evaluating the stability of the coefficients in the equations for the exogenous variables. We did not reject the overidentifying restrictions for these equations. But it is important to recognize the limitation of this result. This just states that the coefficients in the exogenous variables equations-how much area and population are explaining distance from the equator and vice-versa-are stable, and not that the coefficients of interest are stable.

An interesting exercise would be to expand the splits used in this paper to achieve overidentification of all the endogenous interactions and determine if the coefficients are different across sub-samples. This can be achieved if the data is a panel, for example, and we use decades as different splits. Unfortunately, in this paper, the assumption that the coefficients in the four equations of interest are stable across the samples has to remain a maintained assumption.

\section{IV.3 OLS versus IV}

The IV literature estimating the impact of institutions on income usually finds that the coefficient is larger than the OLS estimate. There are several potential explanations for this. First, there may be large errors-in-variables and settler mortality can be instrumenting for it. Second, the feedback from income to institutions could be negative. Third, the instrument may be invalid in that it belongs in the income equation. The results we have presented help resolve this ambiguity.

First, we find that the feedback is in general positive - as the standard intuition would suggest. Richer countries in general can afford better institutions. We also find that variables that are highly correlated with settler mortality - such as distance to the equator-enter the income equation, suggesting that part of the upward bias in the IV estimates could be the result of the instrument not being entirely valid.

Finally, there is the question of whether IH can deal directly with the errors-invariables in the data. The model that we have presented relies on the assumption that heteroskedasticity exists in the data, and that this heteroskedasticity is the outcome of differences in the variances of the structural shocks. As a result, the methodology can deal with errors in variables if we can assume that the variance of the errors-in-variables' shock remains unchanged across the splits. In other words, we have to assume that the change in the variance that is observed across sub-samples still is due to a shift in the structural variances and not to the fact that some sub-sample has a larger error-invariables than the other. This implies that to deal with errors-in-variables we require a somewhat strong assumption. If the split would have been performed by separating developed and developing economies it is clear that this assumption would have been wrong. But our splits are based on geographical alignment and according to whether countries were colonized or not. Therefore, developed and developing economies are 
both represented in the sub-samples. ${ }^{7}$ Thus, this assumption could perhaps be justified. Consequently, the fact that we can deal with some form of errors in variables is a major advantage of our procedure. By contrast, the IV literature assumes that the instrument is orthogonal to both the income shocks and to the measurement errors in the institutions. ${ }^{8}$

\section{Conclusions}

The approach we have taken here serves as a useful robustness check on a large, important, and influential body of research on the determinants of income differences across countries. It also allows us to probe further on the interrelationships among the endogenous variables than the IV literature has been able to do. Some of our results reinforce findings that have already been reported: most importantly, we find a strong causal impact from economic institutions (rule of law) to incomes. Others are novel: one of our most intriguing results is the strong negative effect of trade openness on democracy. Yet other results weigh in on one side of prevailing controversies: for example, our findings on the impact of openness on incomes are in line with papers that have reported negative or insignificant results (e.g. RST) and contradict papers with positive results (e.g., FR).

In closing, we emphasize the need to subject the IH approach itself to further robustness checks. As we indicated above, it would be useful to come up with plausible alternative splits and to be able to test for coefficient stability across sub-samples directly.

\footnotetext{
${ }^{7}$ Some of the poorer countries in the world, namely Ethiopia and Afghanistan, have never been colonized.

${ }^{8}$ The error in variables is equivalent to a common shock and the relaxation of the assumption that the structural shocks have zero covariance. To solve the problem of identification we were to need additional regimes. See Rigobon and Sack (2003b) for a model in which the zero covariance of the structural shocks is relaxed. See also Hogan and Rigobon (2002).
} 


\section{References}

Acemoglu, Daron, Simon Johnson, and James A. Robinson, "The Colonial Origins of Comparative Development: An Empirical Investigation," American Economic Review, 91, 5, December 2001, 1369-1401.

Acemoglu, Daron, and Simon Johnson, "Unbundling Institutions,” MIT, July 2003.

Alcalá, F., and Antonio Cicconé, "Trade and Productivity," Paper presented at the NBER Summer Institute, June 2002.

Broda, Christian and David Weinstein. (2003) "Globalization and the Gains from Variety", Columbia University, Mimeo.

Caporale, G. M., Cipollini, A., and Demetriades, P. (2002a). "Monetary policy and the exchange rate during the Asian crisis: Identification through heteroskedasticity", CEMFE, Mimeo.

Caporale, G. M., Cipollini, A., and Spagnolo, N. (2002b), “Testing for contagion: A conditional correlation analysis", CEMFE, Mimeo.

Diamond, Jared, Guns, Germs, and Steel, New York: W.W. Norton \& Co., 1997.

Dollar, David, and Aart Kraay, "Institutions, Trade and Growth," Carnegie Rochester Conference Series on Public Policy, 2002.

Dollar, David, and Aart Kraay, "Institutions, Trade and Growth: Revisiting the Evidence," World Bank, January 2003.

Easterly, W., and Ross Levine, "Tropics, Germs, and Crops: How Endowments Influence Economic Development," Journal of Monetary Economics, January 2003, volume 50 .

Evans, M., and R. Lyons "How is Macro News Transmitted to Exchange Rates?" NBER Working Paper 9433, January 2003.

Fisher, F. M. (1976). “The Identification Problem in Econometrics”, Robert E. Krieger Publishing Co., New York, second edition.

Frankel, Jeffrey, and David Romer, "Does Trade Cause Growth?" American Economic

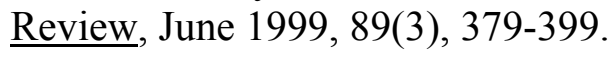

Glaeser, Edward L., Rafael La Porta, Florencio Lopez-de-Silanes, and Andrei Shleifer, "Do Institutions Cause Growth?” NBER Working Paper No. 10568, June 2004 
Hogan, Vincent and Roberto Rigobon (2002) "Using Unobserved Supply Shocks to Estimate the Returns to Education", MIT, mimeo

Hviding Ketil and Luca Ricci (2003) “The Effect of Reserves on Exchange Rate Volatility", IMF, mimeo.

Kaufmann, D., A. Kraay, and P. Zoido-Lobatón, “Governance Matters II-Updated Indicators for 2000/01," World Bank Policy Research Department Working Paper No. 2772, Washington D.C., 2002.

Kaufmann, Daniel, and Aart Kraay, “Growth Without Governance,” Economia, 2002.

Klein, Roger and Francis Vella (2003) "Identification and Estimation of the Triangular Simultaneous Equations Model in the Absence of Exclusion Restrictions Through the Presence of Heteroskedasticity" Rutgers, Mimeo.

Knack, Stephen and Keefer, Philip, "Institutions and Economic Performance: Empirical Tests using Alternative Measures of Institutions," IRIS Working Paper \#109, 1995.

Leamer, Edward (1981) "Is it a demand curve, or is it a supply curve? Partial identification through inequality constraints" Review of Economics and Statistics, August, 63 (3), pp. 319-27.

Pattillo Catherine, Poirson Helene, and Luca Ricci (forthcoming), "The Channels through Which External Debt Affects Growth”, Brookings Institutions Trade Forum.

Rigobon, Roberto (2000) "A simple test for stability of linear models under heteroskedasticity, omitted variable, and endogenous variable problems" September. MIT Mimeo.

Rigobon, Roberto (2002a) "The Curse of Non-investment Grade Countries". Journal of Development Economics, Volume 69, Issue 2, December, pp. 423-449.

Rigobon, Roberto (2002b) "Contagion: How to measure it?" in "Preventing Currency Crises in Emerging Markets" Editors: Sebastian Edwards and Jeffrey Frankel, The University Chicago Press, Chicago, pp 269-334.

Rigobon, Roberto (2003a) "Identification Through Heteroskedasticity." Review of Economics and Statistics, forthcoming.

Rigobon, Roberto (2003b) "On the Measurement of the International Propagation of Shocks: Are they Stable?" Journal of International Economics, forthcoming.

Rigobon, Roberto and Brian Sack (2002) "'The impact of monetary policy on asset prices" MIT mimeo. 
Rigobon, Roberto and Brian Sack (2003a) "Spillovers Across U.S. Financial Markets", MIT mimeo.

Rigobon, Roberto and Brian Sack (2003b) "Measuring the Reaction of Monetary Policy to the Stock Market", Quarterly Journal of Economics, 2003, vol. 118, issue 2, pages 639-669.

Rodríguez, Francisco, and Dani Rodrik, "Trade Policy and Economic Growth: A Skeptic's Guide to the Cross-National Evidence," Macroeconomics Annual 2000, eds. Ben Bernanke and Kenneth S. Rogoff, MIT Press for NBER, Cambridge,MA, 2001.

Rodrik, Dani, Arvind Subramanian, and Francesco Trebbi, "Institutions Rule: The Primacy of Institutions over Geography and Integration in Economic Development" NBER Working Paper, November 2002 (forthcoming, Journal of Economic Growth).

Sachs, Jeffrey, “Institutions Don't Rule: Direct Effects of Geography on Per Capita Income," National Bureau of Economic Research Working Paper No. 9490, February 2003.

Sentana, E. (1992). "Identification of multivariate conditionally heteroskedastic factor models", LSE, FMG Discussion Paper, 139.

Sentana, E. and Fiorentini, G. (2001) "Identification, estimation and testing of conditional heteroskedastic factor models", Journal of Econometrics, 102(2):143—164.

Wright, P. G. (1928). "The Tariff on Animal and Vegetable Oils" The Institute of Economics. The Macmillan Company, New York. 


\section{Appendix}

\begin{tabular}{|c|c|c|c|}
\hline \multicolumn{2}{|c|}{ Not Colonized } & \multicolumn{2}{|c|}{ Colonized } \\
\hline Afghanistan & Liberia & Algeria & Kiribati \\
\hline Albania & Libya & Angola & Lao PDR \\
\hline American Samoa & Liechtenstein & Antigua and Barbuda & Lesotho \\
\hline Andorra & Lithuania & Argentina & Macao, China \\
\hline Armenia & Luxembourg & Aruba & Madagascar \\
\hline Austria & Macedonia, FYR & Australia & Malawi \\
\hline Azerbaijan & Marshall Islands & Bahamas, The & Malaysia \\
\hline Bahrain & Micronesia, Fed. Sts. & Bangladesh & Maldives \\
\hline Belarus & Moldova & Barbados & Mali \\
\hline Belgium & Monaco & Belize & Malta \\
\hline Bosnia and Herzegovina & Mongolia & Benin & Mauritania \\
\hline Bulgaria & Netherlands & Bermuda & Mauritius \\
\hline Channel Islands & Northern Mariana Islands & Bhutan & Mayotte \\
\hline China & Norway & Bolivia & Mexico \\
\hline Croatia & Oman & Botswana & Morocco \\
\hline Cyprus & Palau & Brazil & Mozambique \\
\hline Czech Republic & Poland & Brunei & Myanmar \\
\hline Denmark & Portugal & Burkina Faso & Namibia \\
\hline Eritrea & Qatar & Burundi & Nepal \\
\hline Estonia & Romania & Cambodia & Netherlands Antilles \\
\hline Ethiopia & Russian Federation & Cameroon & New Caledonia \\
\hline Faeroe Islands & Samoa & Canada & New Zealand \\
\hline Finland & San Marino & Cape Verde & Nicaragua \\
\hline France & Saudi Arabia & Cayman Islands & Niger \\
\hline Georgia & Slovak Republic & Central African Republic & Nigeria \\
\hline Germany & Slovenia & Chad & Pakistan \\
\hline Greece & Spain & Chile & Panama \\
\hline Hungary & Sweden & Colombia & Papua New Guinea \\
\hline Iceland & Switzerland & Comoros & Paraguay \\
\hline Iran, Islamic Rep. & Syrian Arab Republic & Congo, Dem. Rep. & Peru \\
\hline Iraq & Taiwan & Congo, Rep. & Philippines \\
\hline Ireland & Tajikistan & Costa Rica & Puerto Rico \\
\hline Isle of Man & Thailand & Cote d'Ivoire & Reunion \\
\hline Israel & Tonga & Cuba & Rwanda \\
\hline Italy & Turkey & Djibouti & Sao Tome and Principe \\
\hline Japan & Turkmenistan & Dominica & Senegal \\
\hline Jordan & Ukraine & Dominican Republic & Seychelles \\
\hline Kazakhstan & United Arab Emirates & Ecuador & Sierra Leone \\
\hline Korea, Dem. Rep. & United Kingdom & Egypt, Arab Rep. & Singapore \\
\hline Korea, Rep. & Uzbekistan & El Salvador & Solomon Islands \\
\hline Kuwait & Vanuatu & Equatorial Guinea & Somalia \\
\hline Kyrgyz Republic & Virgin Islands (U.S.) & Fiji & South Africa \\
\hline Latvia & West Bank and Gaza & French Polynesia & Sri Lanka \\
\hline Lebanon & Serbia/Montenegro & Gabon & St. Kitts and Nevis \\
\hline & & Gambia, The & St. Lucia \\
\hline & & Ghana & St. Vincent and the Grenadines \\
\hline & & Greenland & Sudan \\
\hline & & Grenada & Suriname \\
\hline & & Guam & Swaziland \\
\hline
\end{tabular}




$\begin{array}{ll}\text { Guatemala } & \text { Tanzania } \\ \text { Guinea } & \text { Togo } \\ \text { Guinea-Bissau } & \text { Trinidad and Tobago } \\ \text { Guyana } & \text { Tunisia } \\ \text { Haiti } & \text { Uganda } \\ \text { Honduras } & \text { United States } \\ \text { Hong Kong, China } & \text { Uruguay } \\ \text { India } & \text { Venezuela, RB } \\ \text { Indonesia } & \text { Vietnam } \\ \text { Jamaica } & \text { Yemen, Rep. } \\ \text { Kenya } & \text { Zambia } \\ & \text { Zimbabwe }\end{array}$


Horizontal

\begin{tabular}{|c|c|c|c|}
\hline Andorra & Korea, Rep. & Aruba & Algeria \\
\hline Afghanistan & Kuwait & Angola & Ecuador \\
\hline Albania & Lao PDR & Netherlands Antilles & Eritrea \\
\hline United Arab Emirates & Lebanon & Argentina & Ethiopia \\
\hline Armenia & Liechtenstein & Antigua and Barbuda & Gabon \\
\hline Australia & Sri Lanka & Burundi & Ghana \\
\hline Austria & Lithuania & Benin & Guinea \\
\hline Azerbaijan & Luxembourg & Burkina Faso & Gambia, The \\
\hline Belgium & Latvia & Bahamas, The & Guinea-Bissau \\
\hline Bangladesh & Macao, China & Belize & Equatorial Guinea \\
\hline Bulgaria & Monaco & Bermuda & Grenada \\
\hline Bahrain & Moldova & Bolivia & Guatemala \\
\hline Bosnia and Herzegovina & Maldives & Brazil & Guyana \\
\hline Belarus & Macedonia, FYR & Barbados & Honduras \\
\hline Brunei & Myanmar & Botswana & Haiti \\
\hline Bhutan & Mongolia & Central African Republic & Jamaica \\
\hline Switzerland & Malaysia & Canada & Kenya \\
\hline Channel Islands & Netherlands & Chile & St. Kitts and Nevis \\
\hline China & Norway & Cote d'Ivoire & Liberia \\
\hline Cyprus & Nepal & Cameroon & Libya \\
\hline Czech Republic & New Zealand & Congo, Rep. & St. Lucia \\
\hline Germany & Oman & Colombia & Lesotho \\
\hline Denmark & Pakistan & Comoros & Morocco \\
\hline Egypt, Arab Rep. & Philippines & Cape Verde & Madagascar \\
\hline Spain & Papua New Guinea & Costa Rica & Mexico \\
\hline Estonia & Poland & Cuba & Mali \\
\hline Finland & Korea, Dem. Rep. & Cayman Islands & Malta \\
\hline France & Portugal & Djibouti & Mozambique \\
\hline Faeroe Islands & Qatar & Dominica & Mauritania \\
\hline United Kingdom & Romania & Dominican Republic & \\
\hline Georgia & Russian Federation & & \\
\hline Greece & Saudi Arabia & & \\
\hline Greenland & Singapore & & \\
\hline Hong Kong, China & San Marino & & \\
\hline Croatia & Slovak Republic & & \\
\hline Hungary & Slovenia & & \\
\hline Indonesia & Sweden & & \\
\hline Isle of Man & Syrian Arab Republic & & \\
\hline India & Thailand & & \\
\hline Ireland & Tajikistan & & \\
\hline Iran, Islamic Rep. & Turkmenistan & & \\
\hline Iraq & Turkey & & \\
\hline Iceland & Taiwan & & \\
\hline Israel & Ukraine & & \\
\hline Italy & Uzbekistan & & \\
\hline Jordan & Vietnam & & \\
\hline Japan & West Bank and Gaza & & \\
\hline Kazakhstan & Yemen, Rep. & & \\
\hline Kyrgyz Republic & Cambodia & & \\
\hline
\end{tabular}

